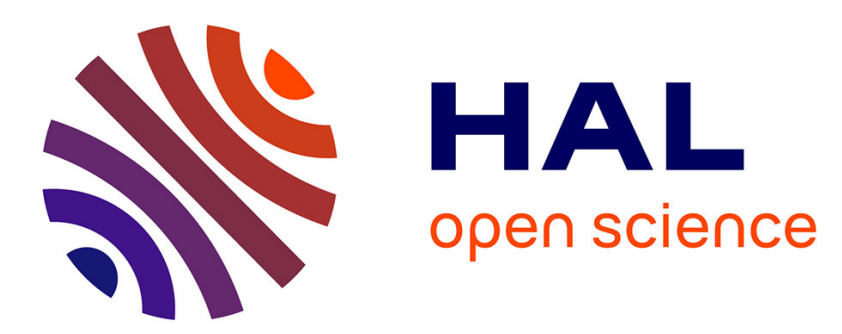

\title{
Treatment of Strontium Hexaferrite Powder Synthesized Conventionally to Produce High Coercivity
}

\author{
S. Seyyed Ebrahimi, Aj. Williams, N. Martinez, A. Ataie, A. Kianvash, C. \\ Ponton, I. Harris
}

\section{- To cite this version:}

S. Seyyed Ebrahimi, Aj. Williams, N. Martinez, A. Ataie, A. Kianvash, et al.. Treatment of Strontium Hexaferrite Powder Synthesized Conventionally to Produce High Coercivity. Journal de Physique IV Proceedings, 1997, 07 (C1), pp.C1-325-C1-326. 10.1051/jp4:19971129 . jpa-00254771

\section{HAL Id: jpa-00254771 https://hal.science/jpa-00254771}

Submitted on 1 Jan 1997

HAL is a multi-disciplinary open access archive for the deposit and dissemination of scientific research documents, whether they are published or not. The documents may come from teaching and research institutions in France or abroad, or from public or private research centers.
L'archive ouverte pluridisciplinaire HAL, est destinée au dépôt et à la diffusion de documents scientifiques de niveau recherche, publiés ou non, émanant des établissements d'enseignement et de recherche français ou étrangers, des laboratoires publics ou privés. 


\title{
Treatment of Strontium Hexaferrite Powder Synthesized Conventionally to Produce High Coercivity
}

\author{
S.A. Seyyed Ebrahimi, A.J. Williams, N. Martinez, A. Ataie, A. Kianvash*, C.B. Ponton and I.R. Harris \\ School of Metallurgy and Materials, The University of Birmingham, Edgbaston, Birmingham B15 2TT, \\ U.K. \\ * Department of Ceramics, Faculty of Engineering, The University of Tabriz, P.O. Box 711, Tabriz, Iran
}

\begin{abstract}
Strontium hexaferrite powder, produced conventionally from strontium carbonate and iron oxide has been treated in nitrogen and hydrogen atmospheres and then calcined in air. Magnetic measurements after the gas treatment stage indicated a marked decrease of intrinsic coercivity and an increase in saturation magnetisation. During the calcination stage there was a recovery of the magnetic properties. The material now exhibited a remanence and saturation magnetisation close to that of the starting hexaferrite, but a very much higher intrinsic coercivity. The highest coercivity obtained was around $400 \mathrm{kA} / \mathrm{m}$, which is very high for a hexaferrite powder, particularly one synthesized conventionally, without extensive milling. The high coercivity was attributed to a much finer grain size.
\end{abstract}

\section{INTRODUCTION}

A novel method of processing hexaferrites, in order to produce an increased intrinsic coercivity without decreasing the saturation magnetisation has been reported for commercial and hydrothermally synthesized materials $[1,2]$. By this method, low coercivity can be produced by heat treating the powders in the presence of hydrogen, nitrogen or carbon. High coercivity can then be achieved by a post-gas treatment calcination in air. The optimised conditions of treatment for conventionally synthesized material in both hydrogen and nitrogen atmospheres are presented elsewhere $[3,4]$.

The authors have studied in this work, the effect of processing on the phase composition, morphology and magnetic properties of strontium hexaferrite with a comparison between the effects of the hydrogen and nitrogen treatments.

\section{EXPERIMENTAL PROCEDURe}

The initial material was strontium hexaferrite synthesized conventionally from strontium carbonate and iron oxide calcined under optimum conditions. This material was treated in hydrogen or nitrogen and then calcined again in air.

$\mathrm{X}$-ray powder diffraction analysis (Co $K \alpha$ radiation) was used for phase identification. The microstructure and morphology was studied by a high resolution scanning electron microscope. The magnetic measurements were performed on a vibrating sample magnetometer operating up to a maximum field of $1100 \mathrm{kA} / \mathrm{m}$.

\section{RESULTS AND DISCUSSIONS}

The magnetic measurements show a great decrease of coercivity and remanence with a marked increase of saturation magnetisation after hydrogen treatment (Fig.1.a). After the subsequent calcination, the remanence and saturation magnetisation indicated values close to the initial values but the intrinsic coercivity was much higher. The magnetic measurements for nitrogen treated powders are shown in Fig.1.b. The behaviour of the material during the nitrogen treatment is similar to that of the hydrogen treatment but the kinetics of the nitrogen treatment are much slower. The increase of intrinsic coercivity for the nitrogen treated and calcined is less than that of the hydrogen treated and calcined material.

The XRD traces indicate a reduction of the hexaferrite phase to various phases during gas treatment. Fig.2.a shows the XRD pattern of strontium hexaferrite after hydrogen treatment in which the diffraction peaks of the hexaferrite phase are no longer visible, but the peaks of $\mathrm{Fe}, \mathrm{FeO}$ and $\mathrm{Sr}_{7} \mathrm{Fe}_{10} \mathrm{O}_{22}$ are evident. The great decrease of coercivity and the marked increase of saturation magnetisation can therefore be attributed to the magnetically soft nature of iron. In the nitrogen treatment the reduction rate is slower and has only proceeded as far as the formation of $\mathrm{Fe}_{3} \mathrm{O}_{4}$ and $\mathrm{Sr}_{7} \mathrm{Fe}_{10} \mathrm{O}_{22}$ (Fig.2.b). After the subsequent calcination, a recovery of the hexaferrite phase occurs and XRD traces show only the peaks for this phase. References 5 to 7 were used to identify the diffraction peaks.

An interesting point of this process is that the microstructure after recalcination is different from that before gas treatment. It is believed that during the processing each hexaferrite grain is divided into sub-grains (Fig.3) which are smaller than the critical size for single domain particles thus leading to the increased intrinsic coercivity. 


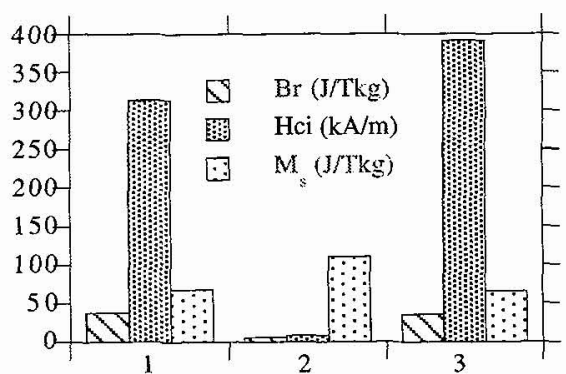

(a)

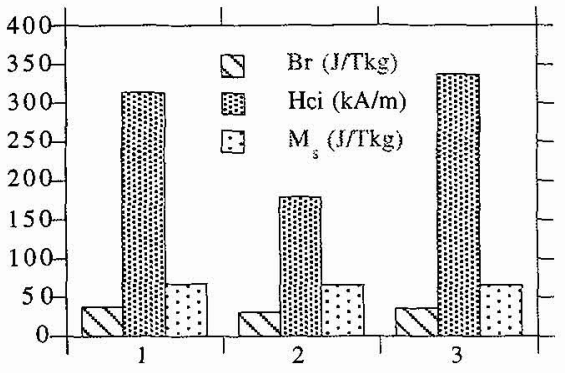

(b)

Fig.1 A comparison of magnetic properties of conventionally synthesized strontium hexaferrite, before gas treatment (1), after gas treatment (2) and after recalcination (3) under optimum processing conditions. (a)Hydrogen and (b)Nitrogen treatment. All measurements are for non-aligned samples.

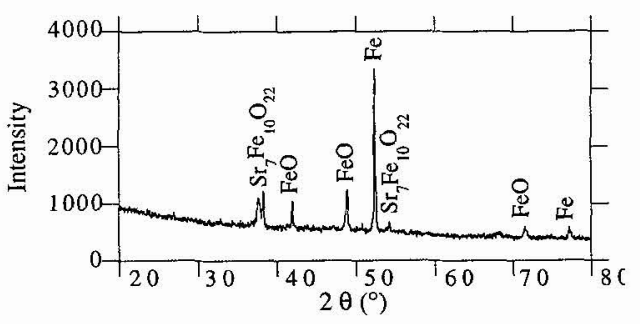

(a)

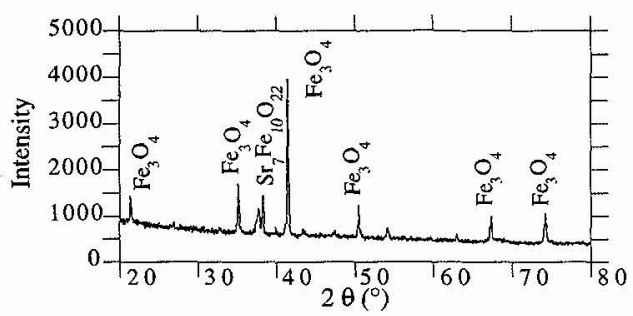

(b)

Fig.2 The XRD patterns of conventionally synthesized strontium hexaferrite after (a)hydrogen and (b) nitrogen treatment, showing the reduction to $\mathrm{Sr}_{7} \mathrm{Fe}_{10} \mathrm{O}_{22}, \mathrm{FeO}$ and $\mathrm{Fe}$ in hydrogen, and to $\mathrm{Fe}_{3} \mathrm{O}_{4}$ and $\mathrm{Sr}_{7} \mathrm{Fe}_{10} \mathrm{O}_{22}$ in nitrogen.

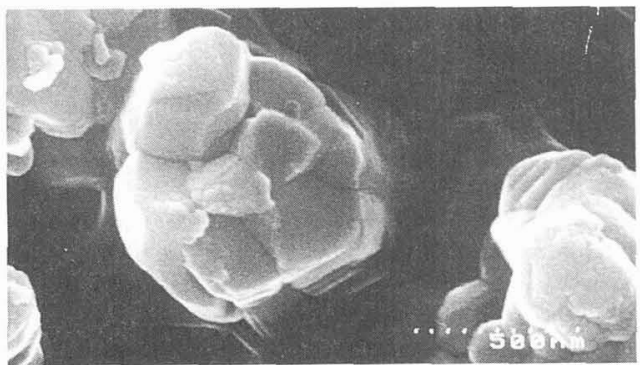

Fig.3 High resolution SEM micrograph of conventionally synthesized strontium hexaferrite after hydrogen treatment and calcination, showing the division of particles into sub-grains with an average diameter less than $500 \mathrm{~nm}$

\section{CONCLUSIONS}

The hydrogen and nitrogen treatment of conventionally synthesized strontium hexaferrite causes the reduction of the hexaferrite phase. The rate of reduction in hydrogen is greater than in nitrogen. The powder becomes magnetically soft after gas treatment. When a subsequent calcination is performed the hexaferrite phase is recovered but with a finer grain size leading to single domain particles and to an intrinsic coercivity as high as $400 \mathrm{kA} / \mathrm{m}$.

\section{Acknowledgements}

The financial and technical support of Tehran University is gratefully acknowledged (SASE, AA).

\section{References}

[1] A.Ataie, I.R.Harris and C.B. Ponton, Patent Application No: PCT/GB95/02758 (November 1995)

[2] A.Ataie, I.R.Harris and C.B. Ponton, J.Mat.Sci., accepted in March 96

[3] S.A.Seyyed Ebrahimi, I.R.Harris, A.Kianvash, C.B. Ponton, to be published

[4] S.A.Seyyed Ebrahimi, I.R.Harris, A.Kianvash, C.B. Ponton, to be published

[5] Brisi, Rolando, Ann. Chim. (Rome), 59, 385 (1969), JCPDS 22-1427

[6] Basta, Mineral. Mag. 31, 431 (1957), JCPDS 11-0614

[7] W.Allen, US Steel Fundamental Res.Lab. Private Communication, JCPDS 06-0615 